\title{
Identifikasi hubungan perilaku vandalisme dengan setting taman kota Lumintang, Denpasar, Bali
}

\author{
Praga Balian Ainun ${ }^{1}$, Ida Ayu Mayun ${ }^{2 \star}$, Anak Agung Gede Sugianthara ${ }^{1}$
}

1. Program Studi Arsitektur Pertamanan, Fakultas Pertanian, Universitas Udayana, Indonesia

2. Program Studi Agroekoteknologi, Fakultas Pertanian, Universitas Udayana, Indonesia

*E-mail: idaayumayun@unud.ac.id

\begin{abstract}
Identification of relationship between vandalism behavior and setting of lumintang city park, Denpasar, Bali Province. Lumintang City Park Denpasar is one of the green open spaces visited by many people. The high intensity of visits leads to some problems, vandalism is one of them. This research aims to analyze the relevance of vandalism activity with environmental factors, study the relationship between vandalism in each setting and learn the appropriate management system to reduce and analyze the behavior of vandalism. Method used in this research was implemented with the technique of (1) observation, (2) questionnaire distribution, (3) literature study, and (4) data analysis. The results showed that the highest activity carried out was to dispose of the garbage is not in place and the highest object affected by vandalism activity is groundcover. Environmental factors that affect waste disposal activities are out of place, limited waste facilities, the presence of previous garbage and small waste bins, while the setting that affects the placement of facilities is not strategic or not in accordance with the point of gathering visitors. These problems can be upgraded by proper management of settings and facilities by looking at the factors that affect the activities of the vandalism.
\end{abstract}

Keywords: city park, vandalism, setting

\section{Pendahuluan}

Ruang Terbuka Hijau (RTH) perkotaan adalah bagian dari ruang-ruang terbuka (open spaces) suatu wilayah perkotaan yang diisi oleh tumbuhan, tanaman dan vegetasi (endemik maupun introduksi). Taman Kota Lumintang memiliki luas $30.000 \mathrm{~m}^{2}$ merupakan salah satu bentuk ruang terbuka hijau di Kota Denpasar yang memiliki fungsi sebagai ruang rekreasi, interaksi sosial, sarana pendidikan, dan olahraga.

Pengunjung Taman Kota Lumintang berasal dari berbagai kalangan, seiring dengan meningkatnya intensitas kunjungan akan menyebabkan muncul suatu masalah, salah satunya adalah vandalisme. Vandalisme merupakan segala macam perilaku yang menyebabkan kerusakan atau penghancuran benda pribadi atau publik (Haryadi dan Setiawan, 1995). Vandalisme yang umumnya terjadi diantaranya membuang sampah tidak pada tempatnya, mencoret-coret fasilitas, menginjak tanaman pada area taman yang sudah diberi papan larangan menginjak tanaman.

Salah satu cara yang dapat digunakan untuk mengurangi aktivitas vandalisme yaitu diperlukanya perancangan dan pengelolaan setting yang tepat dalam suatu kawasan. Setting adalah lokasi-lokasi pada tapak atau areal tertentu yang telah diplotkan sebelumnya (Haryadi dan Setiawan, 1995). Studi ini bertujuan untuk menjaga kelestarian Ruang Terbuka Hijau Kota Denpasar sebagai Taman Kota maupun manfaat bagi masyarakat. Ditinjau dari hubungan dengan karakteristik pelaku vandalisme, meliputi jenis kelamin, tingkat pendidikan, usia, jumlah pelaku, aktivitas pelaku, objek yang dituju pelaku, dan faktor yang mendorong pelaku.

Rumusan masalah pada penelitian ini yaitu bagaimana hubungan antara prilaku vandalisme terhadap setting lingkungannya di Taman Kota Lumintang Denpasar, apakah faktor setting tapak mempengaruhi aksi vandalisme di Taman Kota Lumintang Denpasar, serta bagaimana sistem pengelolaan yang tepat dalam mengurangi dan mencegah perilaku vandalisme di Taman Kota Lumintang Denpasar.

\section{Bahan dan Metode}

\subsection{Tempat dan Waktu Penelitian}

Penelitian ini dilaksanakan di Jl. Mulawarman, Lumintang, Dauh Puri Kaja, Denpasar Utara, Provinsi Bali. Penelitian dimulai pada bulan Oktober 2016 - Juni 2017. 


\subsection{Bahan dan Alat} Denpasar.

Bahan yang digunakan dalam penelitian ini yaitu : peta dasar dan peta fasilitasTaman Kota Lumintang

Alat yang digunakan dalam penelitian ini yaitu : lembar pertanyaan (kuesioner), kamera handphone, komputer, dan software pengelolaan data (Microsoft Excel yang dipergunakan untuk analisis data).

\subsection{Metode Penelitian}

Penelitian ini menggunakan metode analisis deskriptif eksprolatif yang terdiri dari : teknik observasi, penyebaran kuesioner, studi pustaka, dan analisis data.

\subsubsection{Tehnik Observasi}

Tehnik Observasi merupakan penentuan landasan penelitian dan untuk mengumpulkan data yang ada di lapang. Dalam hal ini terdapat dua tahapan dalam melakukan observasi diantaranya : (1) Pra-observasi bertujuan menentukan landasan utama penelitian yang mencakup penetapan tujuan penelitian, penyusunan rencana kerja, penentuan lokasi penelitian dan pengumpulan informasi yang diperlukan untuk memulai penelitian, (2) Observasi merupakan pengumpulan data dengan mengamati kegiatan-kegiatan dan mendokumentasikan hal-hal yang dianggap perlu untuk menunjang penelitian ini yang ada di lapangan.

\subsubsection{Penyebaran Kuesioner}

Penyebaran kuesioner dilakukan dengan tujuan untuk mengetahui faktor lingkungan yang mendorong para pengunjung untuk melakukan tindakan vandalisme pada tapak. Teknik sampling yang digunakan dalam pembagian kuesioner adalah nonprobability sampling. Penyebaran kuesioner dilakukan di empat bagian yang telah ditetapkan sebagai tempat penelitian, yaitu area selatan, area utara, area timur dan area barat pada Taman Kota Lumintang Denpasar.

Jumlah keseluruhan kuesioner yang dibagikan sebanyak 120 kuesioner yang pada masing-masing zona dibagikan sebanyak 30 kuesioner terdiri dari : (1) 10 kuesioner untuk mengetahui faktor lingkungan yang mendorong pelaku tindakan vandalime menulis atau menggambar pada bagian fasilitas, (2) 10 kuesioner untuk mengetahui faktor lingkungan yang mendorong pelaku tindakan vandalism mematahkan atau mengambil bagian tanaman, dan (3) 10 kuesioner untuk mengetahui faktor lingkungan yang mendorong pelaku tindakan vandalisme membuang sampah tidak pada tempatnya. Kriteria responden yaitu yang didapati sedang melakukan tindakan vandalisme dengan batasan usia 12 tahun ke atas dan dapat menulis serta membaca.

\subsubsection{Studi Pustaka}

Studi pustaka merupakan teknik pengumpulan data dengan mengumpulkan laporan hasil penelitian dan teori-teori yang tercantum dalam literatur, internet atau referensi yang dapat menunjang penelitian.

Data yang digunakan dalam penelitian ini adalah data primer dan data sekunder. Data primer dikumpulkan melalui kuesioner dengan pelaku vandalisme, data tersebut meliputi umur pelaku, tingkat pendidikan, jumlah pelaku, aktivitas vandalisme yang dilakukan, obyek yang dikenai vandalisme, dan faktor lingkungan yang mempengaruhi aksi vandalisme.Sedangkan data sekunder yaitu pengumpulan data-data yang diperoleh dari sumber-sumber kepustakaan, data tersebut meliputi kondisi dan lokasi penelitian, peta dasar dan sistem pengelolaan kawasan.

\subsubsection{Analisis Data}

Metode yang digunakan pada penelitian ini yaitu analisis deskriptif eksploratif merupakan suatu metode yang dilakukan dengan cara mengumpulkan data dari hasil wawancara, catatan lapangan, foto dan data yang dapat dijadikan petunjuk untuk digunakan dalam mencari suatu data dan kemudian ditarik kesimpulan dari suatu masalah dan disusun secara sistematis berdasarkan data yang telah dikumpulkan (Moleong, 2002).

Proses penyajian data dilakukan dengan mengidentifikasi pelaku dan obyek yang dikenai vandalisme dalam pengamatan langsung ke dalam bentuk data kuantitatif. Data ini kemudian diolah menggunakan Microsoft Excel untuk memperoleh tabel jumlah aktifitas vandalisme dan tabel jumlah ragam obyek yang menjadi sasaran aktivitas vandalisme.Data yang diperoleh disajikan ke dalam bentuk diagram batang, penyajian dalam bentuk diagram batang dapat mempermudah membaca besar data dari suatu kategori serta proses perbandingan dari beberapa kelompok data sehingga dapat langsung diketahui perbedaan dan persamaannya.

\section{Hasil dan Pembahasan}

\subsection{Setting Utara}

Obyek yang menjadi sasaran aktivitas vandalisme pada setting utara yaitu pohon, semak, penutup tanah dan bangku taman (Tabel 1) sedangkan obyek meja taman, gazebo, tempat sampah, lampu taman, media informasi dan pengumuman serta arena bermain tidak ada dalam setting ini. 
Tabel 1. Sasaran Obyek Vandalisme di Setting Utara

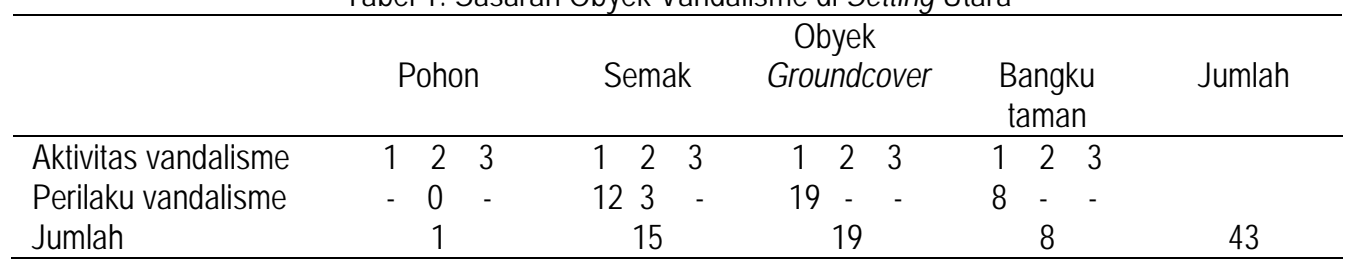

Faktor lingkungan yang mempengaruhi timbulnya aktivitas vandalisme 1 yaitu terbatasnya ketersediaan tempat sampah dan keberadaan sampah sebelumnya (Tabel 2). Sedangkan untuk jumlah fasilitas tempat sampah pada setting utara ini belum mencukupi yaitu dua tempat sampah kecil dan dua tempat sampah berukuran besar, namun yang menjadi kesalahan pada setting ini yaitu letak tempat sampah tidak strategis atau tidak disesuaikan dengan tempat berkumpulnya pengunjung. Banyaknya jumlah sampah yang dibuang pada obyek semak dan penutup tanah hal ini dipengaruhi oleh terbatasnya fasilitas tempat duduk yang disediakan pada setting ini yaitu enam tempat duduk, sedangkan rata-rata kunjungan yang ada di setting ini yaitu lima belas hingga dua puluh lima orang sehingga pengunjung memilih duduk pada penutup tanah.

Tabel 2. Faktor Lingkungan yang Mempengaruhi Aktivitas Vandalisme di Setting Utara

\begin{tabular}{llcc}
\hline $\begin{array}{c}\text { Tipe } \\
\text { Vandalisme }\end{array}$ & \multicolumn{1}{c}{ Faktor Lingkungan } & Berpengaruh & $\begin{array}{c}\text { Tidak } \\
\text { Berpengaruh }\end{array}$ \\
\hline \multirow{2}{*}{ Aktivitas 1 } & a. Terbatasnya ketersediaan tempat sampah & $70 \%$ & $30 \%$ \\
& b. Keberadaan sampah sebelumnya & $60 \%$ & $40 \%$ \\
Aktivitas 2 & a. Dalam jangkauan tangan & $30 \%$ & $70 \%$ \\
& b. Keindahan atau keunikan bagian tanaman & $20 \%$ & $80 \%$ \\
Aktivitas 3 & a. Berada pada lokasi sepi & $100 \%$ & $0 \%$ \\
& b. Keberadaan coretan sebelumnya & $20 \%$ & $80 \%$ \\
\hline
\end{tabular}

Keterangan :

1. Aktivitas vandalisme $1:$ Membuang sampah tidak pada tempatnya

2. Aktivitas vandalisme 2 : Merusak atau mengambil tanaman

3. Aktivitas vandalisme 3 : Mencoret-coret fasilitas

Obyek pohon Cerbera manghas dikenai aktivitas vandalisme 2. Faktor lingkungan tidak memberikan pengaruh terhadap dilakukanya aktivitas vandalisme 2 (Tabel 2), hal ini dikarenakan aktivitas vandalisme pada setting ini tidak disebabkan oleh kesalahan setting tetapi disebabkan oleh kesalahan pengguna taman itu sendiri.

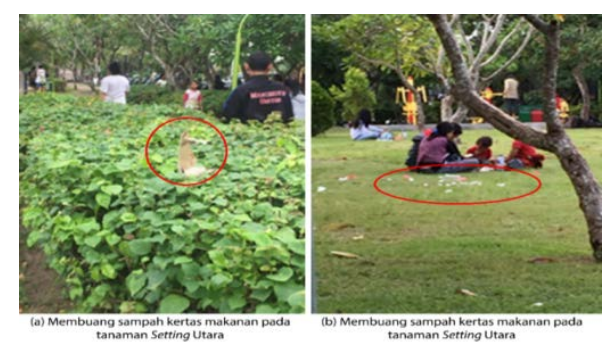

Gambar 1. Sasaran Obyek Vandalisme di Setting Utara

Faktor lingkungan yang mempengaruhi aktivitas vandalisme 3 yaitu berada pada lokasi sepi dan keberadaan coretan sebelumnya tidak mempengaruhi aktivitas vandalisme tersebut (Tabel 2), coretan yang ada sebelumnya pada obyek tempat penyimpanan fasilitas yaitu coretan pilox sehingga membekas pada obyek tersebut.

\subsection{Setting Selatan}

Aktivitas vandalisme tertinggi didapati pada setting selatan, dari 10 obyek yang diamati terdapat enam obyek yang menjadi sasaran aktivitas vandalisme diantaranya : pohon, semak, penutup tanah, bangku taman, 
meja taman, dan arena bermain (Tabel 3), jumlah sasaran aktivitas vandalisme tertinggi dilakukan pada penutup tanah sebesar 42 aktivitas. Pada saat penelitian berlangsung untuk obyek tempat sampah, lampu taman, media informasi dan pengumuman serta gazebo tidak dikenai aktivitas vandalisme, untuk obyek gazebo tidak terdapat pada setting ini.

Tabel 3. Sasaran Obyek Vandalisme di Setting Selatan

\begin{tabular}{|c|c|c|c|c|c|c|c|c|c|c|c|c|c|c|c|}
\hline \multirow[b]{3}{*}{$\begin{array}{l}\text { Aktivitas } \\
\text { vandalisme }\end{array}$} & \multirow{2}{*}{\multicolumn{3}{|c|}{ Pohon }} & \multirow{2}{*}{\multicolumn{2}{|c|}{ Semak }} & \multicolumn{10}{|c|}{ Obyek } \\
\hline & & & & & & Ground & cover & $\begin{array}{c}\mathrm{Me} \\
\text { tam }\end{array}$ & & & $\begin{array}{l}\text { angku } \\
\text { aman }\end{array}$ & & $\begin{array}{l}\text { Are } \\
\text { bern }\end{array}$ & $\begin{array}{l}\text { na } \\
\text { nain }\end{array}$ & Jumlah \\
\hline & 1 & 23 & 3 & $\begin{array}{ll}12 \\
\end{array}$ & 3 & 12 & 3 & 12 & 3 & 1 & 23 & & 12 & 23 & \\
\hline $\begin{array}{l}\text { Perilaku } \\
\text { vandalisme }\end{array}$ & 2 & 1 & - & 133 & - & 735 & - & 1 & - & 6 & $-\quad-$ & & 16 & - 1 & \\
\hline Jumlah & & 3 & & 16 & & 42 & & 1 & & & 6 & & 1 & 7 & 85 \\
\hline
\end{tabular}

Tabel 4. Faktor Lingkungan yang Mempengaruhi Aktivitas Vandalisme di Setting Selatan.

\begin{tabular}{clcc}
\hline $\begin{array}{c}\text { Tipe } \\
\text { Vandalisme }\end{array}$ & \multicolumn{1}{c}{ Faktor Lingkungan } & Berpengaruh & $\begin{array}{c}\text { Tidak } \\
\text { Berpengaruh }\end{array}$ \\
\hline \multirow{2}{*}{ Aktivitas 1 } & a. Terbatasnya ketersediaan tempat sampah & $90 \%$ & $10 \%$ \\
& b. Keberadaan sampah sebelumnya & $40 \%$ & $60 \%$ \\
\multirow{2}{*}{ Aktivitas 2 } & a. Dalam jangkauan tangan & $100 \%$ & $0 \%$ \\
& b. Keindahan atau keunikan bagian tanaman & $40 \%$ & $60 \%$ \\
\multirow{2}{*}{ Aktivitas 3 } & a. Berada pada lokasi sepi & $80 \%$ & $20 \%$ \\
& b. Keberadaan coretan sebelumnya & $70 \%$ & $30 \%$ \\
\hline
\end{tabular}

Keterangan :

1. Aktivitas vandalisme 1 : Membuang sampah tidak pada tempatnya

2. Aktivitas vandalisme 2 : Merusak atau mengambil tanaman

3. Aktivitas vandalisme 3 : Mencoret-coret fasilitas

Faktor lingkungan yang mempengaruhi timbulnya aktivitas vandalisme 1 yaitu terbatasnya fasilitas tempat sampah yang disediakan (Tabel 4) dengan jumlah fasilitas : tiga tempat sampah berukuran kecil dan dua tempat sampah berukuran besar. Fasilitas tempat sampah menjadi terbatas disebabkan oleh penempatan fasilitas tidak disesuaikan dengan titik berkumpulnya pengunjung dan banyaknya pengunjung membuang sampah pada obyek pohon (Cerbera manghas) semak (Graptophyllum pictum, Ixora acuminata Roxb, dan Acalypha siamensis), bangku taman dan arena bermain. Selama penelitian berlangsung, tanaman semak yang dibiarkan rimbun dan terkesan tidak terawat memudahkan pelaku vandalisme menyelipkan sampah pada obyek semak.

Faktor lingkungan yang mempengaruhi pengunjung melakukan aktivitas vandalisme 2 pada obyek penutup tanah (Pennisetum purpureum) yaitu mudah dijangkau (Tabel 4). Pada saat penelitian berlangsung banyak pengunjung yang menginjak rumput Pennisetum purpureum dikarenakan tidak adanya pagar pembatas dan digunakan sebagai jalan pintas untuk menuju ke kawasan sungai yang ada di sebelah Taman Lumintang Kota Denpasar. 
Faktor lingkungan yang mempengaruhi aktivitas vandalisme 3 yaitu berada pada lokasi sepi dan adanya keberadaan coretan sebelumnya (Tabel 4), pelaku mencoret obyek dengan tipe-x dan spidol sehingga membekas pada obyek tersebut (Gambar 2). Berdasarkan wawancara dengan pengunjung, diketahui bahwa semakin banyak coretan yang ada sebelumnya maka akan memicu untuk timbulnya lebih banyak coretan pada suatu obyek.

\subsection{Setting Barat}
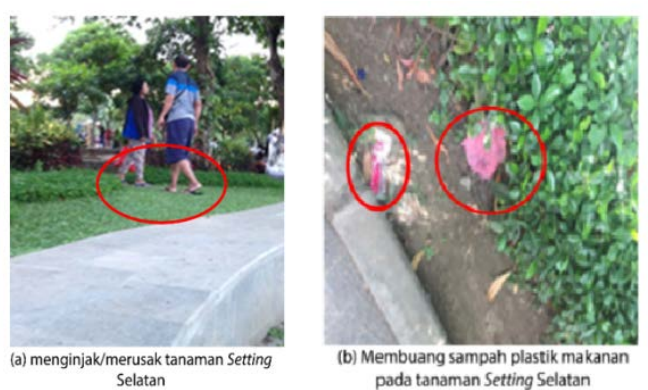

Gambar 2. Sasaran Obyek Vandalisme di Setting Selatan

Obyek yang menjadi sasaran aktivitas vandalisme pada setting ini diantaranya pohon (Cerbera manghas dan Plumeria sp), semak (Bougainvillea s, Aerva sanguinolenta L., dan Syzygium olein), penutup tanah, gazebo, meja taman, dan bangku taman (Tabel 5), sedangkan obyek arena bermain, tempat sampah, lampu taman, dan media informasi dan pengumuman tidak dikenai aktivitas vandalisme. Untuk obyek arena bermain tidak terdapat pada setting ini.

Tabel 5. Sasaran Obyek Vandalisme di Setting Barat

\begin{tabular}{lrlllllllllllllllllll}
\hline & Pohon & Semak & Groundcover & Gazebo & $\begin{array}{c}\text { Obyek } \\
\text { Meja } \\
\text { taman }\end{array}$ & $\begin{array}{c}\text { Bangku } \\
\text { taman }\end{array}$ & Jumlah \\
\hline $\begin{array}{l}\text { Aktivitas } \\
\text { vandalisme }\end{array}$ & 1 & 2 & 3 & 1 & 2 & 3 & 1 & 2 & 3 & 1 & 2 & 3 & 1 & 2 & 3 & 1 & 2 & 3 & \\
$\begin{array}{l}\text { Perilaku } \\
\text { vandalisme }\end{array}$ & 1 & 3 & - & 14 & 7 & - & 14 & - & - & & 7 & - & 4 & 5 & - & $2-$ & 14 & - & - & \\
Jumlah & 4 & & 21 & & 14 & & 11 & & 7 & & 14 & 71 \\
\hline
\end{tabular}

Tabel 6. Faktor Lingkungan yang Mempengaruhi Aktivitas Vandalisme di Setting Barat

\begin{tabular}{clcc}
\hline \multirow{2}{*}{$\begin{array}{c}\text { Tipe } \\
\text { Vandalisme }\end{array}$} & \multicolumn{1}{c}{ Faktor Lingkungan } & Berpengaruh & Tidak Berpengaruh \\
& \multicolumn{1}{c}{ Aktivitas 1 } & & \\
& a. Terbatasnya ketersediaan tempat sampah & $60 \%$ & $40 \%$ \\
& b. Keberadaan sampah sebelumnya & $70 \%$ & $30 \%$ \\
\multirow{2}{*}{ Aktivitas 2 } & a. Dalam jangkauan tangan & $90 \%$ & $10 \%$ \\
& b. Keindahan atau keunikan bagian tanaman & $40 \%$ & $60 \%$ \\
\multirow{2}{*}{ Aktivitas 3 } & a. Berada pada lokasi sepi & $50 \%$ & $50 \%$ \\
& b. Keberadaan coretan sebelumnya & $90 \%$ & $10 \%$ \\
\hline
\end{tabular}

Keterangan :

1. Aktivitas vandalisme 1 : Membuang sampah tidak pada tempatnya

2. Aktivitas vandalisme 2 : Merusak atau mengambil tanaman

3. Aktivitas vandalisme 3 : Mencoret-coret fasilitas 
Faktor lingkungan yang mempengaruhi aktivitas vandalisme 1 yaitu terbatasnya ketersediaan tempat sampah dan keberadaan sampah sebelumnya (Tabel 6). Jumlah fasilitas tempat sampah pada setting ini tiga

buah tempat sampah berukuran kecil dan tiga buah tempat sampah berukuran besar. Pada setting barat tanaman semak dibiarkan tidak terawat dan tidak tertata dengan rapi, sehingga terjadi penumpukan sampah pada obyek semak sehingga menjadi sasaran pengunjung untuk membuang sampah.

Obyek semak (sansevieria) menjadi sasaran aktivitas vandalisme 2. Faktor lingkungan yang mempengaruhi pelaku melakukan aktivitas vandalisme dua yaitu dalam jangkauan tangan (Tabel 6) dengan tinggi obyek semak yaitu $0,30 \mathrm{~m}$. Faktor lain yang tidak adanya pembatas antara pengguna taman dengan tanaman sehingga pengguna bisa mengambil bagian tanaman dengan mudah.

Aktivitas vandalisme 3 ditemukan pada obyek gazebo. Faktor lingkungan yang mempengaruhi pelaku vandalisme adalah berada pada lokasi sepi dan sudah terdapatnya coretan sebelumnya (Tabel 6). Coretan yang ada sebelumnya pada obyek gazebo yaitu coretan dengan menggunakan benda tajam sehingga membekas dan coretan tersebut sangat sulit dihilangkan, sedangkan pada saat penelitian pelaku mencoret obyek dengan menggunakan pulpen sehingga mudah dihilangkan (Gambar 3).

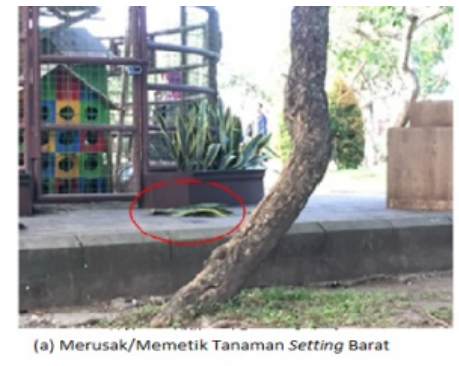

Gambar 3. Sasaran Obyek Vandalisme di Setting Barat

\subsection{Setting Timur}

Aktivitas vandalisme pada setting timur dari sepuluh obyek yang diamati hanya terdapat enam obyek yang menjadi sasaran aktivitas vandalisme (Tabel 7). Obyek yang menjadi sasaran aktivitas vandalisme pada setting ini adalah pohon (Mangifera indica L.) dan (Cerbera manghas), semak (Ixora acuminata Roxb), penutup tanah (Axonopus compressus), gazebo, bangku taman dan lampu taman.

Tabel 7. Sasaran Obyek Vandalisme di Setting Timur

\begin{tabular}{|c|c|c|c|c|c|c|c|c|c|c|c|c|c|c|c|c|c|}
\hline \multirow[b]{3}{*}{$\begin{array}{l}\text { Aktivitas } \\
\text { vandalisme }\end{array}$} & \multirow{2}{*}{\multicolumn{3}{|c|}{ Pohon }} & \multirow{2}{*}{\multicolumn{3}{|c|}{ Semak }} & \multirow{2}{*}{\multicolumn{2}{|c|}{ Groundcover }} & \multicolumn{6}{|c|}{ Obyek } & \multirow{2}{*}{\multicolumn{2}{|c|}{$\begin{array}{l}\text { Lampu } \\
\text { taman }\end{array}$}} & \multirow[b]{2}{*}{ Jumlah } \\
\hline & & & & & & & & & & zeb & & & $\begin{array}{l}\text { angk } \\
\text { man }\end{array}$ & & & & \\
\hline & 1 & 2 & 3 & 1 & 2 & 3 & 12 & 3 & 1 & 2 & 3 & 1 & 2 & 3 & & 23 & \\
\hline $\begin{array}{l}\text { Perilaku } \\
\text { vandalisme }\end{array}$ & - & 9 & - & 7 & 1 & - & $11-$ & - & 1 & - & - & 4 & - & - & $1-$ & - & \\
\hline Jumlah & & 9 & & & 8 & & 11 & & & 1 & & & 4 & & & 1 & 34 \\
\hline
\end{tabular}

Faktor lingkungan yang mempengaruhi aktivitas vandalisme 1 yaitu terbatasnya ketersediaan tempat sampah disediakan (Tabel 8) yaitu empat tempat sampah berukuran kecil dan tiga tempat sampah berukuran besar. Penelitian dilapangan menunjukkan terdapatnya sampah yang digantungkan pada jenis tanaman semak yaitu Ixora acuminata Roxb, pelaku mengatakan kurangnya tempat sampah dan letak tempat sampah yang terlalu jauh menyebabkan pelaku mengantung sampah bungkus makanan tersebut. Selama penelitian berlangsung, hal lain yang menjadi kesalahan pada setting ini yaitu smoking area yang terdapat pada gazebo digunakan sebagai tempat sampah hal ini disebabkan oleh kurang tempat sampah.

Faktor lingkungan yang mempengaruhi pelaku melakukan aktivitas vandalisme 2 yaitu mudah dalam jangkauan (Tabel 8) yang memiliki ketinggian $3 \mathrm{~m}$ dan $4 \mathrm{~m}$. Tetapi pada bagian tanaman Plumeria sp memiliki keunikan dan kenyamanan bagi pelaku dikarenakan bagian tanaman tersebut mudah diduduki dan dipanjat hal tersebut memudahkan terjadinya aktivitas vandalisme. Faktor lingkungan yang mempengaruhi pelaku vandalisme 3 adalah berada pada lokasi sepi dan keberadaan coretan sebelumnya (Tabel 8). Obyek bangku taman dan jalan setapak menjadi sasaran aktivitas vandalisme ketiga mencoret-coret fasilitas pada setting timur. 
Tabel 8. Faktor Lingkungan yang Mempengaruhi Aktivitas Vandalisme di Setting Timur.

\begin{tabular}{llcc}
\hline $\begin{array}{c}\text { Tipe } \\
\text { Vandalisme }\end{array}$ & \multicolumn{1}{c}{ Faktor Lingkungan } & Berpengaruh & $\begin{array}{c}\text { Tidak } \\
\text { Berpengaruh }\end{array}$ \\
\hline \multirow{2}{*}{ Aktivitas 1 } & a. Terbatasnya ketersediaan tempat sampah & $70 \%$ & $30 \%$ \\
& b. Keberadaan sampah sebelumnya & $30 \%$ & $70 \%$ \\
\multirow{2}{*}{ Aktivitas 2 } & a. Dalam jangkauan tangan & $70 \%$ & $30 \%$ \\
& b. Keindahan atau keunikan bagian tanaman & $40 \%$ & $60 \%$ \\
\multirow{2}{*}{ Aktivitas 3 3} & a. Berada pada lokasi sepi & $90 \%$ & $10 \%$ \\
& b. Keberadaan coretan sebelumnya & $90 \%$ & $10 \%$ \\
\hline
\end{tabular}

Keterangan :

1. Aktivitas vandalisme 1 : Membuang sampah tidak pada tempatnya

2. Aktivitas vandalisme 2 : Merusak atau mengambil tanaman

3. Aktivitas vandalisme 3 : Mencoret-coret fasilitas

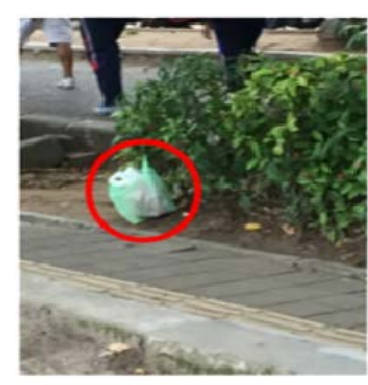

(a) Membuang Sampah Makanan
Setting Timur

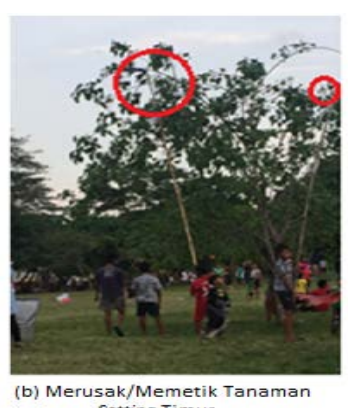

(b) Merusak/Memetik Tanaman
Setting Timur

Gambar 4. Sasaran Obyek Vandalisme di Setting Timur

Berdasarkan penelitian dari keempat setting di atas, obyek tertinggi yang banyak menjadi sasaran aktivitas vandalisme adalah tanaman jenis penutup tanah, dengan nilai pada setting utara 19 pelaku (Tabel 1), setting selatan 44 pelaku (Tabel 3), setting barat 14 pelaku, dan setting timur 11 pelaku (Tabel 7). Penelitian ini sama dengan Annisa (2011) pada setting Kebun Raya Cibodas bahwa obyek tertinggi yang dikenai aktivitas vandalisme adalah tanaman jenis penutup tanah. Hasil penelitian menunjukkan aktivitas vandalisme tertinggi yang dilakukan oleh pengunjung yaitu membuang sampah tidak pada tempatnya, hasil penelitian tersebut didukung oleh dengan penelitian Sawitri dan Subiandono (2001) pada obyek wisata alam Penanjung Pangandaran, bahwa sebagian pengunjung di kawasan wisata melakukan aktivitas membuang sampah tidak pada tempatnya. Aktivitas ini dilakukan dipengaruhi oleh terbatasnya fasilitas tempat sampah, lokasi fasilitas tidak sesuao dengan titik berkumpulnya pengunjung dan adanya beberapa sampah sebelumnya pada masingmasing setting, pernyataan tersebut didukung pula oleh penelitian Rahmawaty (2006) bahwa daya tarik kawasan harus diikuti pengelolaan yang baik dan tersedianya sarana dan prasarana penunjang yang cukup dalam mendukung kegiatan rekreasi.

Rekomendasi atau saran untuk mengurangi aktivitas vandalisme pada taman Kota Lumintang Denpasar adalah :

1) Menambah fasilitas tempat sampah dan melakukan penanganan cepat pada sampah yang telah ada sebelumnya serta pengangkutan sampah secara teratur.

2) Penempatan fasilitas tempat sampah pada titik-titik berkumpulnya pengunjung dan tersebar merata di setiap bagian setting, selain itu desain tempat sampah yang menarik dan besarnya volume untuk kapasitas tempat sampah menjadi salah satu alternatif agar pengunjung membuang sampah pada tempatnya.

3) Memberi jarak titik tanam, perawatan tanaman dengan baik dan membuat topiary untuk tanaman yang rimbun seperti Acalypha siemensis dan Bougainvillea sp. Desain tanaman berbentuk topiary dapat memberikan keunikan, dan menambah nilai estetika pada tanaman tersebut. 
4) Setting timur diperlukan pula penyebaran fasilitas taman. Hal tersebut dapat menjadi alternatif penyebaran pengunjung yang merata sehingga setting timur tidak terkesan sepi.

5) Membuat desain boks tanaman dengan ukuran dan bentuk yang berfungsi sebagai pembatas tanaman agar pengunjung tidak menginjak tanaman dan untuk jarak pintu menuju bawah sungai diarahkan lebih dekat dan tidak memutar sehingga pengunjung tidak menginjak tanaman.

6) Penambahan papan informasi berupa larangan untuk merusak atau mengambil tanaman dan larangan bermain layangan pada taman.

7) Aktivitas vandalisme mencoret-coret pada bagian fasilitas dapat diminimalkan dengan pengawasan dan menindak tegas pelaku vandalisme serta menambahkan lukisan pada tempat duduk dan meja taman sehingga dapat menambah nilai keindahan pada fasilitas tersebut.

8) Pembersihan secara cepat agar tidak menimbulkan coretan - coretan lainnya, dan menambahkan fasilitas seperti tembok untuk kegiatan mural/grafiti sehingga pengguna taman bisa mengalurkan bakatnya.

\section{Simpulan dan Saran}

\subsection{Simpulan}

Berdasarkan hasil penelitian tentang Identifikasi Hubungan Perilaku Vandalisme dengan Setting Taman Kota Lumintang Denpasar dapat disimpulkan sebagai berikut :

1. Ketiga faktor lingkungan yang diidentifikasi yaitu aktivitas membuang sampah tidak pada tempatnya, aktivitas mengambil atau merusak bagian tanaman, dan aktivitas mencoret-coret rata-rata mempengaruhi pelaku untuk melakukan aktivitas vandalisme.

2. Setting pada Taman Kota Denpasar mempengaruhi ketiga aktivitas vandalisme (membuang sampah tidak pada tempatnya, mengambil atau merusak bagian tanaman, dan mencoret-coret fasilitas).

3. Untuk menghindari aktivitas vandalisme yang terjadi dapat dilakukan dengan menambah volume tempat sampah, meletakkan tempat sampah di titik-titik berkumpulnya pengunjung, memelihara dan merawat tanaman dengan teratur dan rapi serta memperbaiki struktur fasilitas yang sudah ada coretan di sekitar taman Kota Lumintang Denpasar.

\subsection{Saran}

Penelitian yang dilakukan saat ini masih memiliki kelemahan dan keterbatasan. Kelemahan tersebut antara lain penelitian ini hanya melihat dampak dari aktivitas vandalisme membuang sampah tidak pada tempatnya, aktivitas vandalisme mengambil atau merusak bagian tanaman dan aktivitas mencoret-coret fasilitas. Untuk penelitian lanjutan yang akan dilakukan dapat membuat perancangan desain setting yang tepat untuk kenyamanan, aman dan indah bagi pengunjung agar aksi vandalisme bisa berkurang.

Hasil yang diperoleh dari penelitian ini salah satunya adalah mengetahui faktor lingkungan yang mendorong pengguna taman melakukan aksi vandalisme pada setiap setting. Oleh karena itu diharapkan pemerintah Kota Denpasar dapat mengelola dan merancang yang tepat Taman Kota Lumintang Denpasar

\section{Daftar Pustaka}

Annisaa, E.P. 2011. Identifikasi Hubungan Perilaku Vandalisme dengan Setting Kebun Raya Cibodas Kabupaten Cianjur. Skripsi (tidak dipublikasikan). Departemen Arsitektur Lanskap, Institut Pertanian Bogor, Bogor.

Haryadi, B. dan Setiawan. 1995. Arsitektur Lingkungan dan Perilaku: Suatu Pengantar ke Teori, Metodologi dan Aplikasi. Direktorat Jendral Pendidikan Tinggi. Jakarta.

Moleong, J.L. 2002. Metodologi Penelitian Kualitatif. PT. Remaja Rosdakarya, Bandung.

Rahmawaty. 2006. Karakteristik Pengunjung Rekreasi dan Obyek Wisata di Taman Hutan Raya Dr.Mohammad Hatta. Karya Tulis. Departemen Kehutanan Universitas Sumatra Utara, Sumatra.

Sawitri,R dan E,Subiandono. 2001. Persepsi dan Perilaku Pengunjung Terhadap Kelestarian Kawasan Taman Wisata Alam Pananjung Pangandaran. Buletin Penelitian Hutan 2001. Hal.29-44. 